\title{
FAKTOR PENYEBAB KETIDAKTUNTASAN MATERI FISIKA PADA PESERTA DIDIK SMAN 13 MAKASSAR
}

\section{CAUSED FACTORS IN INQUIRY OF PHYSICAL MATERIALS IN STUDENTS IN SMAN 13 MAKASSAR}

\author{
${ }^{1)}$ Nurwidyawati, ${ }^{2)}$ Helmi, ${ }^{3)}$ S. Salmiah Sari \\ Universitas Negeri Makassar \\ Kampus UNM Parangtambung Jln. Daeng Tata Raya, Makassar, 90224 \\ ${ }^{1)}$ e-mail : wnur202@gmail.com
}

\begin{abstract}
Abstrak. Faktor Penyebab Ketidaktuntasan Materi Fisika Pada Peserta Didik Sman 13 Makassar. Penelitian ini adalah penelitian ex-post facto yang bertujuan untuk mendeskripsikan faktor-faktor penyebab ketidaktuntasan materi pada peserta didik SMAN 13 Makassar. Variabel dalam penelitian ini adalah ketidaktuntasan materi fisika. Subjek penelitian pada penelitian ini adalah pendidik pada SMAN 13 Makassar. Tehknik pengumpulan data yang digunakan peneliti dalam penelitian ini adalah wawancara, dokumentasi, serta cross check data. Data dari hasil penilitian ini menunjukkan bahwa faktor-faktor yang mempengaruhi ketidaktuntasan materi pada siswa antara lain (1) Tidak terlaksananya RPP dengan baik, (2) kurangnya efisiensi waktu yang digunakan oleh pendidik, (3) penjelasan pendidik yang berulang pada satu sub-bab materi, (4) Kurangnya pengorganisasian materi yang baik dari pendidik, (5) Tidak di berlakukannya pemberian pekerjaan rumah oleh pendidik kepada peserta didik, (6) kurangnya kemampuan peserta didik dalam perhitungan. Ketidaktuntasan materi pada peserta didik ini dilihat dari satu aspek yaitu pendidik. Dimana kurangnya perhatian pendidik pada perencanaan yang matang bagi proses pembelajaran fisika di dalam kelas
\end{abstract}

Kata kunci : Ketidaktuntasan materi, indikator pencapaian, dan efisiensi waktu.

\begin{abstract}
Caused Factors In Inquiry Of Physical Materials In Students In Sman 13 Makassar. This research is an ex-post facto study which aims to describe the factors that cause material incompleteness in students of SMAN 13 Makassar. The variable in this study is the incompleteness of physics subject. The research subjects in this study were teacher at SMAN 13 Makassar. Data collection techniques used by researchers in this study were interviews, documentation, and cross check data. Data from this study shows that the factors that influence incompleteness subject in students include ; (1) the implementation of RPP is not well implemented, (2) lack of time efficiency used by teacher, (3) repeated explanations of teacher in one sub-chapter material, (4) Lack of organizing good material from teacher, (5) Not applying the provision of homework by teacher to students, (6) lack of ability of students in calculation. The material incompleteness in these students is seen from one aspect, namely teacher. Where is the lack of attention of educators on careful planning for the physics learning process in the classroom.
\end{abstract}

Keywords : Incompleteness subject, indicators of achievement, and time efficiency

\section{PENDAHULUAN}

Belajar dan mengajar merupakan dua konsep yang tidak bisa dipisahkan satu sama lain. Belajar menunjukan kepada apa yang harus dilakukan seseorang sebagai peserta didik, Menurut Bloom dalam Asra (2008: 107) Mastery mempunyai arti penguasaan penuh terhadap inti materi pembelajaran, sedangkan menurut Keller dalam Asra (2008: 107) Mastery adalah Performance (penampilan) yang sempurna dalam sejumlah unit pembelajaran tertentu. Sedangkan Learning Berarti belajar atau pembelajaran.

Disisi lain, komponen peserta didik juga turut menentukan keberhasilan dalam proses belajar mengajar. Menurut Hamalik (2013:12) faktor yang menjadi penyebab terjadinya ketidaktuntasan peserta didik dalam belajar yaitu: tidak stabilnya pikiran peserta didik dalam belajar dan kesehatan mental kurang 
dikarenakan rasa rendah diri sebagai akibat kondisi sekolah yang kurang menguntungkan bagi peserta didik. Konsep konsep yang berhubungan dengan konsep-konsep baru yang akan diterimanya harus sudah dikuasai oleh peserta didik. Menurut Sri Anitah Wiryawan (2001: 8.16) seseorang dikatakan memahami sesuatu berarti ia telah mengorganisasikan dan mengutarakan kembali apa yang dipelajarinya dengan menggunakan kalimatnya sendiri. Hal inilah yang juga sangat berpengaruh pada keberhasilan proses belajar mengajar. Peserta didik cenderung mempunyai ingatan yang kurang tepat. Materi pelajaran dipahami seketika itu tetapi lupa jika materi yang sama di tanyakan beberapa hari kemudian. Ingatan akan melekat pada anak-anak yang tergolong berprestasi.

Salah satu tantangan yang harus di hadapi seorang pendidik adalah kepribadian peserta didik yang tak pernah sama. Dalam sebuah kelas, keanekaragaman peserta didik termasuk juga cara belajarnya membuat pendidik harus lebih beradaptasi dengan peserta didik, agar materi yang diajarkan lebih dapat di terima oleh peserta didik sesuai yang diharapkan. Salah satu jurnal international mengatakan bahwa cara belajar seorang peserta didik dan siswi tidak memiliki perbedaan yang signifikan. Karna itu, dalam sebuah kelas, pendidik haruslah lebih pintar dalam mengambil tindakan pengajaran.

Alokasi waktu yang digunakan untuk belajar harus sesuai dengan kemampuan masingmasing peserta didik. setiap peserta didik memiliki potensi dan bakat yang berbeda-beda, di samping waktu yang diperlukan untuk belajar juga tidak sama. Namun kurikulum ini sudah tidak lagi di terapkan dalam dunia pendidikan, karna tak pernah ada pembelajaran tuntas yang benar-benar tuntas didalam kelas.

Mata pelajaran fisika adalah salah satu materi yang tergolong cukup sulit di mengerti oleh peserta didik. Tak jarang banyak peserta didik melewatkan materi-materi yang sebenarnya cukup penting di pahami secara mendalam dikarenakan beberapa pendidik menyampaikan pembelajaran yang pembahasannya keluar dari materi yang seharusnya penting untuk di ajarkan. Sehingga fenomena buta pemahaman peserta didik terus berlanjut dari dulu hingga sekarang. Belum lagi kurikulum 2013 sekarang ini memberikan materi pembelajaran yang semakin tinggi tingkatannya untuk meningkatkan sumber daya anak bangsa. Banyaknya materi juga menuntut pendidik untuk lebih cerdas lagi memilih materi apa saja yang penting untuk di ajarkan dalam kelas dan mana yang perlu peserta didik pelajari di luar pembelajaran kelas.

Faktor lingkungan juga mempengaruhi kecepatan belajar peserta didik dalam menyerap pengetahuan yang di sampaikan oleh pendidik. Peserta didik yang hidup di daerah pertanian akan paham lebih jauh tentang penerapan bercocok tanam, dan tugas pendidik hanya tinggal memberikan sedikit dorongan dengan pemberian pengetahuan yang sesuai dengan pengetahuan dasar mereka.

Dari beberapa latar belakang permasalahan di atas, peneliti berinisiatif untuk mengidentifikasi faktor yang mempengaruhi ketidaktuntasan materi peserta didik di SMA 3 Makassar. agar permasalahan-permasalahan diatas dapat dan pembelajaran selanjutnya peserta didik akan lebih menguasai materi-materi yang lebih sulit dengan modal pemahaman konsep fisika yang mereka miliki nanti.

\section{METODE}

Penelitian ini merupakan penelitian pendidikan kualitatif dengan jenis peneltian expost facto. Pelaksanaan penelitian dilakukan di SMAN 13 Makassar. Data dari penelitian ini di dapat dengan menggunakan teknik wawancara, dokumentasi, dan cross check data dari hasil obsevasi penelitian di dalam kelas selama kurang lebih 2 minggu. Setelah melakukan pengambilan 
data, data akan dikumpulkan dan dianalisis melalui cross check untuk melihat seberapa besar kecocokan antara hasil wawancara, RPP guru, dan hasil dari pengamatan dari peneliti sendiri. Dengan menggunakan analisis deskriptif, peneliti menganalisis hasil penelitian dengan didukung oleh beberapa artikel-artikel yang berhubungan dengan penelitian peneliti untuk memperkuat analisis peneliti. Dengan didukung oleh beberapa media atau rekaman yang diambil peneliti, peneliti menganalisis hasil penelitian dengan fakta-fakta dan artikel penelitian yang relevan.

\section{HASIL DAN PEMBAHASAN}

Dalam penelitian ini, peneliti melakukan penelitian tanpa disadari oleh subjek penelitian itu sendiri. Hal ini dilakukan agar hasil yang didapat oleh peneliti adalah murni kegiatan belajar-mengajar sesuai dengan keseharian subjek penelitian. Baik itu bagi pendidik ataupun peserta didik. Hal ini cukup sulit dilakukan dikarenakan salah satu subjek penelitian, yaitu pendidik cukup sulit untuk di wawancarai mengenai proses pembelajaran yang ia gunanakan.

Tabel 1. Hasil Ulangan Harian Peserta Didik Kelas X IPA 2 Untuk Setiap Butir Soal.

\begin{tabular}{|c|c|c|c|c|}
\hline \multirow{2}{*}{ Siswa } & \multicolumn{3}{|c|}{ Butir soal } & \multirow{2}{*}{$\begin{array}{c}\text { Nilai ulangan } \\
\text { harian }\end{array}$} \\
\hline & 1 & 2 & 3 & \\
\hline 1 & & & & - \\
\hline 2 & $\sqrt{ }$ & & & 20 \\
\hline 3 & $\sqrt{ }$ & $\sqrt{ }$ & & 30 \\
\hline 4 & $\sqrt{ }$ & & & 20 \\
\hline 5 & & & & - \\
\hline 6 & $\sqrt{ }$ & & & 30 \\
\hline 7 & $\sqrt{ }$ & & & 30 \\
\hline 8 & $\sqrt{ }$ & & $\sqrt{ }$ & 40 \\
\hline 9 & $\sqrt{ }$ & & & 20 \\
\hline 10 & $\sqrt{ }$ & & & 20 \\
\hline 11 & $\sqrt{ }$ & $\sqrt{ }$ & & 30 \\
\hline 12 & & & & - \\
\hline 13 & $\sqrt{ }$ & $\sqrt{ }$ & & 30 \\
\hline 14 & $\sqrt{ }$ & & & 30 \\
\hline 15 & $\sqrt{ }$ & & & 20 \\
\hline 16 & $\sqrt{ }$ & & & 25 \\
\hline 17 & & & & 15 \\
\hline 18 & $\sqrt{ }$ & & & 30 \\
\hline 19 & $\sqrt{ }$ & & $\sqrt{ }$ & 35 \\
\hline 20 & & & & 15 \\
\hline 21 & $\sqrt{ }$ & $\sqrt{ }$ & $\sqrt{ }$ & 70 \\
\hline 22 & $\sqrt{ }$ & $\sqrt{ }$ & & 35 \\
\hline 23 & $\sqrt{ }$ & & $\sqrt{ }$ & 50 \\
\hline
\end{tabular}




\begin{tabular}{llll}
\hline 24 & $\sqrt{ }$ & $\sqrt{ }$ & 35 \\
\hline 25 & & & 15 \\
\hline 26 & $\sqrt{ }$ & & 30 \\
\hline 27 & $\sqrt{ }$ & & 10 \\
\hline 28 & $\sqrt{ }$ & $\sqrt{ }$ & $\sqrt{ }$ \\
\hline 29 & $\sqrt{ }$ & & 70 \\
\hline 30 & $\sqrt{ }$ & & 30 \\
\hline 31 & $\sqrt{ }$ & $\sqrt{ }$ & 30 \\
\hline 32 & $\sqrt{ }$ & $\sqrt{ }$ & 35 \\
\hline 33 & $\sqrt{ }$ & & 35 \\
\hline & & & 20
\end{tabular}

peneliti mendapatkan soal evaluasi untuk mengukur ketuntasan indikator yang dicapai oleh peserta didik.

1. Sebuah benda bermassa $9 \mathrm{Kg}$ bergerak dengan kecepatan $18 \mathrm{~km} / \mathrm{s}$. Gerak benda tersebut dihentikan oleh penghalang dalam selang waktu $1 \mathrm{~s}$, hitunglah:

a) momentum awal benda.

b) impuls yang diberikan penghalang.

c) gaya rata-rata yang diberikan penghalang.

2. Dua bola dengan massa $3 \mathrm{~kg}$ dan $5 \mathrm{~kg}$ bergerak searah diatas lantai yang licin dengan kecepatan $8 \mathrm{~m} / \mathrm{s}$ dan $4 \mathrm{~m} / \mathrm{s}$. Beberapa saat kemudian terjadi tumbukkan lenting sebagian dengan koefisien restitusi 0,5. Berapa kecepatan benda setelah tumbukkan?

3. Sebuah benda dengan massa $3000 \mathrm{~kg}$ bergerak ke kanan dengan kecepatan 18 $\mathrm{km} / \mathrm{jam}$ dan bertumbukkan dengan benda lain bermassa $1000 \mathrm{~kg}$ yang bergerak ke kiri dengan kecepatan $36 \mathrm{~km} / \mathrm{jam}$. Setelah tumbukan kedua benda menyatu. Hitung kecepatan kedua benda tersebut setelah tumbukkan!

Berdasarkan data-data di atas, beberapa faktor penyebab ketidaktuntasan materi dilihat dari proses pembelajaran dan hasil evaluasi siswa, ditemukan bahwa standar ketercapaian kompetensi dasar tak terpenuhi seluruhnya, khususnya untuk standar isi, dan proses, beberapa faktor penyebab ketidak-tuntasan maeri juga di dapat dari ketakberlaksaannya RPP oleh pendidik, serta tidak tercapainya ketuntasan indikator.

\section{SIMPULAN}

Dari hasil penlitian dan pembahasan dapat disimpulan bahwa faktor yang mempengaruhi ketidaktuntasan materi peserta didik yaitu (1) Tidak terlaksananya RPP dengan baik. (2) Kurangnya efisiensi waktu yang digunakan oleh pendidik. (3) Penjelasan pendidik yang berulang pada satu sub materi. (4) Kurangnya pengorganisasian materi yang baik dari pendidik. (5) Tidak diberlakukannya pemberian pekerjaan rumah oleh pendidik kepada peserta didik. (6) Kurangnya kemampuan peserta didik dalam perhitungan.

\section{DAFTAR RUJUKAN}

Asra, Sumiati. 2008. Metode Pembelajaran. Bandung: Wacana Prima

Bariroh, Annisaul. 2014. Faktor-Faktor Yang Mempengaruhi Ketidaktuntasan Hasil Belajar Pada Mata Pelajaran Geografi di Kelas $X$ Tahun Ajaran 2012/2013 SMA Mardi Siwi Surabaya. UNESA

Djamarah, Syaiful Bahri. 2011. Psikolog Belajar. PT Asdi Mahasatya

Wiryaman, Sri Anitah. 2001. Strategi Belajar Mengajar. Universitas Terbuka 